\title{
Boceto Crítico sobre Gabriela Mistral
}

\author{
A Ricardo Tudela
}

I UCILA Godoy es el nombre de Gabriela Mistral. Se inicia en $\perp$ la vida literaria durante su adolescencia. En efecto, a los quince años de edad colabora en periódicos de su provincia. La producción de aquella etapa no ha sido compilada. Por lo tanto, es muy difícil tener un juicio de conjunto. Sin embargo, de las pocas piezas vueltas a publicar, en el presente, se puede afirmar que son melancólicas y sugestivas.

Su vida de modesta profesora primaria provinciana se enriquece con el imponderable tesoro de un amor desventurado. Tal vez el fragmento de su obra que la hizo famosa (la parte titulada "Dolor", de su libro Desolación) se puede calificar como un milagro literario, milagro producido por el choque violento del enstteño amoroso y la cruda realidad de la existencia objetiva.

En 1907 conoce a un hombre joven que le provoca el hechizo del amor, hechizo que expresa en el poema titulado "El encuentro". Ese hallazgo la va a vestir de hondas "llagas". Porque el legítimo amor es hermano gemelo del dolor.

El proceso de aquella pura y ardiente pasión está traducido, en todo su desarrollo y varias alternativas, en "Dolor", verdadero fragmento autobiográfico de la autora. El verbo poético en los veintisiete ${ }^{1}$ poemas que lo integran va de la esperanza hasta la desilusión, de la plenitud gozosa hasta el desgarramiento lancinante.

En "Dolor" se pueden leer "Los sonetos de la muerte", versos antirretóricos y grávidos de pasión. Sobre estas pequeñas canciones (según su etimología) conviene detenerse para comprender un tanto la trayectoria de su vida literaria. 
En 1914, la Sociedad de Artistas y Escritores realiza unos Juegos Florales. Pues bien, el 22 de diciembre obtiene la flor natural, la corona de laurel y la medalla de oro, una mujer desconocida en las letras nacionales. Su nombre un tanto exótico, de evocación bíblica y provenzal; su verso que, como el viento de su apellido literario, barre las fórmulas establecidas y dice con desusada franqueza la pasión que le quema su espíritu y entraña; su ausencia del acto consagratorio, se unen y suman para suscitar interés.

Desde aquella justa de poesía, ${ }^{2}$ si se me permite la frase, el nombre de Gabriela Mistral se hace famoso en el mundo literario hispanoamericano. Diarios y revistas le solicitan colaboraciones y el poeta entrega sus doloridas y límpidas estancias a revistas que se llaman Los Diez, Selva Lirica, Nosotros.

En "Dolor" figura el poema titulado "El ruego", poema que es una dramática imploración y en el cual el verbo se triza en patético frenesi de ansia y esperanza.

El suicidio, como se sabe, está prohibido por la doctrina católica, pues el hombre tiene por objeto servir y honrar a Dios con su vida, según la religión nombrada. El amado de Lucila Godoy, empero, no posee la calma suficiente y termina, con sus días, en acción volitiva. La autora sabe que pide por un hombre condenado por su doctrina religiosa, mas no ceja, porque siente a Dios como Señor del perdón. De ahí que matice sus ruegos y llegue hasta las sutilezas en la dialéctica :

Me replicas, severo, que es de plegaria indigno el que no untó de preces sus dos labios febriles, y se fué aquella tarde sin esperar tu signo, trizándose las sienes como vasos sutiles.

Pero yo, mi Señor, te arguyo que he tocado, de la misma manera que el nardo de su frente, todo su corazón dulce y atormentado iy tenía la seda del capullo naciente!

Más adelante define y describe el amor con estas palabras de profunda emoción y sabiduría :

Y amar (bien sabes de eso) es amargo ejercicio; un mantener los párpados de lágrimas mojados, un refrescar de besos las trenzas del cilicio conservando, bajo ellas, los ojos extasiados. 
Pocas veces el idioma poético español ha logrado más penetrante captación del hecho amoroso como en "El ruego", poema en el cual las voces se quiebran plenas de sentido emocional comunicativo. Lo patético y dramático se aglutinan sumando su fuerza, y dan al acento implorante los matices de la esperanza difícil, pero no imposible de alcanzar:

¡Dí el perdón, dílo al fin! Va a esparcir en el viento la palabra el perfume de cien pomos de olores al vaciarse; toda agua será deslumbramiento; el yermo echará flores y el guijarro esplendores.

Se mojarán los ojos oscuros de las fieras, $y$, comprendiendo el monte que de piedra forjaste llorará por los párpados blancos de sus neveras: iToda la tierra tuya sabrá que perdonaste! :

En "El ruego", Gabriela Mistral tiene una de sus más cabales creaciones. En pocas oportunidades, el instrumento expresivo lexical se ha plasmado en más vibrantes sonidos y en más profundo sentimiento que en estas estancias rogativas.

En 1922, el eminente profesor español de la Columbia University de Nueva York, Federico de Onís, consigue dar a la estampa Desolación. Esa fecha marca una época en la literatura chilena. El alma aseada y apasionada de Gabriela Mistral entrega al público hispánico su mensaje de singular calidad lírica.

En España, el catedrático Manuel de Montoliú la estudia con la hondura de su erudición; en Colombia, el poeta Julio Mercado la elogia con bella elocuencia en un fino ensayo; en Costa Rica, el profesor Roberto Brenes-Mesén la examina con atildada efusión crítica; en todas las repúblicas americanas se la lee y comenta, se la exalta o se la niega. Parece condición del genio ser a la par celebrado y censurado.

Los temas poéticos de Gabriela Mistral se pueden dividir en los siguientes aspectos: el amor, la naturaleza, lo elegíaco y lo lírico. E1 primero se puede stubdividir a su vez en amores: a Dios, al amado, a los niños, a la madre y a la enseñanza. $\mathrm{El}$ segundo, en una visión desolada, primero, y en tna visión tranquila de lo americano, después.

Un análisis, aunque somero, de cada uno de estos temas es indispensable para tener un concepto global de su obra. He juzgado 
ya el amor al amado, amor patético y expresión novedosa tanto en la forma como en el contenido. Ahora voy a examinar los otros puntos señalados.

El amor a Dios lo manifiesta Gabriela Mistral en casi toda su obra, pero el acento en que ese amor se acerca al misticismo, sin alcanzar el poeta chileno "las relaciones sobrenaturales, secretas, por las cuales eleva a Dios a la criatura sobre las limitaciones de su naturaleza y la hace conocer un mundo superior...", ${ }^{4}$ se halla traducido en los siguientes poemas: "La Cruz de Bistolfi", "Al oído del Cristo", "Viernes Santo" y "A la Virgen de la Colina" de $D \mathcal{e}$ solación; "Hablando al Padre", "Angel Guardián" y "El himno cotidiano" de Ternura. Sin embargo, aunque estas poesías no son místicas, en el rigor del concepto alcanzan un alto rango religioso. De una religiosidad alimentada en la rica palabra bíblica y en la suave voz teresiana.

El amor a los niños se encuentra desarrollado a lo largo de sus tres libros: Desolación, Ternura y Tala. Se vierte en sus "Rondas", "Jugarretas", "Otras canciones", "Albricias". En especial, las primeras han conseguido una sincera aceptación entre los niños.

La $v$ dice:

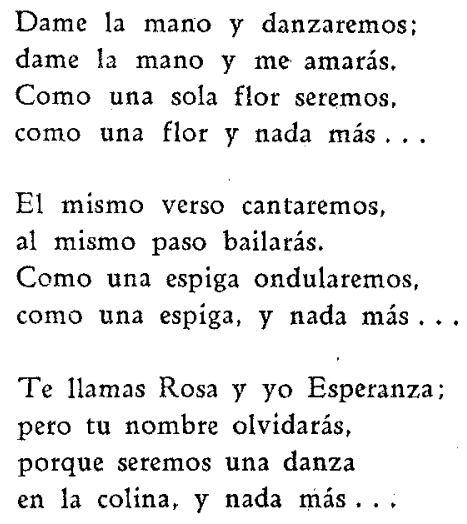

El amor a la madre o, mejor dicho, a la maternidad, lo expresa en sus numerosas canciones de cuna, en las cuales logra finos matices expresivos. Pero donde el hallazgo intuicional alcanza su más alto valor estético es, primero, en los "Poemas de las madres" y, después, en "Poema de la madre más triste". ${ }^{5}$ 
El amor a la enseñanza está vertido especialmente en "La maestra rural", "El corro luminoso", "Himno de la Escuela Gabriela Mistral". Hay otros poemas que la autora denomina "Casi escolares" " en que, asimismo, trata de la escuela y su entrañable afecto por esta forma de vida y trabajo. El primero de los mencionados poemas, del presente parágrafo, se inspira en su "santa hermana Emelina, quien fué su única maestra real, alma apostólica de donde yo he sacado la estampa de mi maestra rural". 7 Dicha poesía está dedicada al profesor Federico de Onís, y sus dos primeras estrofas dicen :

\footnotetext{
La Maestra era pura. "Los suaves hortelanos", decía, "de este predio, que es predio de Jesús, han de conservar puros los ojos y las manos, guardar puros sus óleos, para dar clara luz."

La Maestra era pobre. Su reino no es humano. (Así en el doloroso sembrador de Israel.) Vestía sayas pardas, no en joyaba su mano iy era todo su espíritu un inmenso joyel!
}

La naturaleza, en la poesía de Gabriela Mistral, aparece fuertemente coloreada por su temperamento. En otros términos, es una naturaleza estilizada. El estilo es, sin duda, un segmento de proyección del yo creador.

- En su primera etapa poética, o sea desde 1912 a 1922, años durante los cuales compone Desolación, la naturaleza tiene mucho de patético y desolado. Es el paisaje magallánico o es la visión del árbol magro e inelegante que se llama espino. Además, se advierte otro tipo de visión. Una visión un tanto abstracta en sus poemas titulados "Otoño", "Arbol muerto", "La montaña de noche", "Doña Primavera", "Verano". Esa época que abarca Desolación (19221923-1926) y Ternura (1924) es superada en Tala (1938).

En efecto, en el último libro mencionado la naturaleza aparece muty matizada, no sólo de vivencias nuevas, sino de asociaciones de orden latinoamericanas. Es el canto que abarca el continente colombino el que logra su más plena plasmación en sus dos himnos: "Sol del trópico" y "Cordillera". Asimismo, consigue muy finas traducciones poéticas en "El maíz", "Mar Caribe" y "Recado para las Antillas". Es ésta una naturaleza variada que se nutre de historia y 
tradición, de nuevos modos de ver y de sentir las tierras americanas. En "Sol del trópico" canta:

Hazme las sangres, y las leches
y los tuétanos, y los llantos.
Mis sudores y mis heridas
sécame en lomos y en costados
y otra vez integra incorpórame
a los coros que te danzaron
los coros mágicos, mecidos
sobre Palenque y Tihuanaco.

Lo elegíaco posee rasgos novedosos en la poesía de mi egregia paisana. El dolor por la pérdida de seres queridos se traduce en una serie de recuerdos que se afiligranan en curiosas expresiones entre literarias y coloquiales. "In memoriam" - elegía a Amado Nervo- es un caso típico de lo que he afirmado. Asimismo, parecido procedimiento, aunque alquitarado de más sutiles formas literarias, se puede observar en la sección titulada "Muerte de mi madre", de Tala.

"Lo lírico - acaso parezca de pronto absurdo referirse al lirismo, en forma autónoma, en una obra principalmente lírica; sin embargo, me voy a explicar-, lo lírico en Gabriela Mistral tiene un departamento separado, en cierto modo. Su producción, como he dicho, traduce diversos aspectos de su experiencia. Pues bien, entiendo por lírico en el presente caso lo íntimo y subjetivo. Es este punto de su poesía el que la autora denomina: "Vida" en Desolación; "Criaturas", "Saudade", "Historias de loca" y "Alucinación" en Tala.

Lo lírico en Gabriela Mistral posee alta dignidad literaria. Jamás se transforma en íntima y desvergonzada confesión, sino que se proyecta en puras introspecciones. En Desolación, los poemas se titulan "La mujer fuerte", "La mujer estéril", "Canto del justo", "El suplicio", "Futuro"; en Ternura, "Caricia", "Dulzura"; en Tála, "La ley del tesoro", "Riqueza", "La copa", "La medianoche", "Dos ángeles", "Todas íbamos a ser reinas", "Cosas", "La flor del aire", "La sombra", "El fantasma". Pero nada mejor que reproducir una de estas piezas de antología. ¿Cuál? Es preciso elegir. Difícil tarea. La más pequeña: Riqueza, por bella y por honda:

Tengo la dicha fiel y la dicha perdida: 


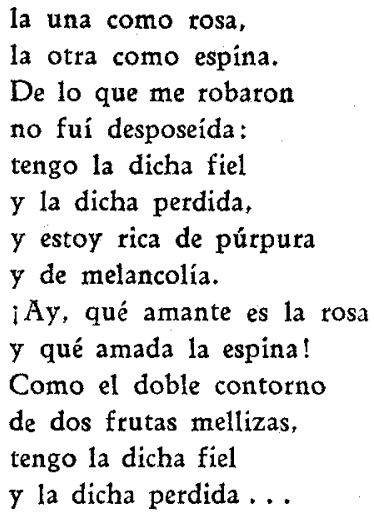

He terminado este brevísimo análisis de la poesía de mi preclara compatriota: he tocado sólo sus puntos esenciales. Queda el tema casi entero para un estudio completo, sereno, lúcido. ¿Quiera el tiempo permitirme tan subido placer estético para el futuro!



La prosa de Gabriela Mistral es de rara categoría. Desde su mocedad cultiva esta forma de la escritura literaria. Sin embargo, un juicio crítico es asaz difícil, porque su autora no ha reunido en libro su abundante producción prosática (valga el neologismo, pues el término prosaica que usaría el rigoroso purista es impropio por lo peyorativo).

La obra en prosa (no aludo a sus poemas prosáticos, como es obvio comprender) se puede dividir en dos clases: artículos periodísticos y recados.

En los primeros, trata de tópicos de actualidad: educación, feminismo y temas de muy variada ley. Son, sin duda, significativos para estudiar el alcance de su labor completa; pero su valor fenece al paso del tiempo. Del periodismo se puede decir lo que Malherbe manifiesta de la juventud: vive el espacio de una mañana.

En los segundos, en cambio, tanto por el tema como por el estilo, hay un valor más permanente. Son de gran subjetivismo y su gracia descansa en el tono de intimidad coloquial que logra en casi todos. Sus recados (recado es - no olvidarlo- mensaje oral) poseen, además, valía renovadora en la composición de la prosa americana. 
En su contexto brillan voces arcaicas, provincianas y familiares. No obstante, no es el ingrediente idiomático solo el que les presta singularidad, sino la suma que fluye como un plus de su corpus literario.

Por desgracia, estas observaciones no las puede comprobar el lector, y el crítico literario no debe laborar a base de la creencia que se le preste. Ha de trabajar con pruebas que, si las puede dar en un ensayo exhaustivo de crítica, no caben en un modesto boceto de aproximación en simpatía y cordialidad, como el presente.

\section{Norberto Pinilla, Universidad de Chile.}

\section{NOTAS}

1 Ver Desolación. Nueva York, Instituto de las Españas, 1922. 248 pp.

2 Los poemas premiados y los dedicados a la Reina del torneo lírico, pueden verse en la compilación de Julio Munizaga Ossandon titulada El libro de los juegos florales. Santiago, Zig-Zag, s. f. y sin numeración de páginas. Seguramente de 1915.

3 Las citas están tomadas de la primera edición de Desolación.

4 Pedro Sáinz Rodríguez, Introducción a la historia de la literatuta mistica en España, p. 20. Madrid, Voluntad, 1927. 310 pp.

5 Ver Desolación, p. 239. Santiago, Nascimento, 1926. Tercera edición. $342 \mathrm{pp}$.

6 Ver Tetnuta, Buenos Aires, Espasa-Calpe, 1945. 190 pp.

7 Ver Gabriela Mistral, Antología, p. 18. Santiago, Zig-Zag, 1941. $318 \mathrm{pp}$. 